\title{
La construcción de poblaciones utilizando los censos de población en Latinoamérica
}

\author{
Santiago J. Molina*
}

\begin{abstract}
LOVEMAN, Mara. National colors: racial classification and the state in Latin America. New York: Oxford University Press, 2014, xix+377p.
\end{abstract}

National colors es una rica examinación comparativa del trabajo de los órganos del estado responsables de la colección de datos con la utilización de los censos poblacionales en Latinoamérica. Mara Loveman hace una importante contribución al estudio de las consecuencias sociales de las categorías etno-raciales para la ciudadanía, cuando las categorías son utilizadas y reafirmadas por el estado. Ésta investigación se enfoca en el desarrollo de los censos de población de Argentina, Bolivia, Brasil, Chile, Colombia, Costa Rica, Cuba, La República Dominicana, Ecuador, El Salvador, Guatemala, Honduras, México, Nicaragua, Panamá, Paraguay, Perú, Uruguay y Venezuela en los últimos dos siglos. Bajo un marco teórico con una extensa base sociológica, Loveman cubre un territorio con profundidad histórica y comparativa.

Loveman identifica y trata tres problemas empíricos correspondientes a tres periodos de la historia de Latinoamérica: Primero, cuando los países Latinoamericanos se independizaron de los imperios Ibéricos, ¿por qué fue que la mayoría de las emergentes naciones independientes retuvieron las categorías raciales y de casta que dominaban durante la conquista? Segundo, ¿por qué fue que la mayoría de estos nuevos estados luego abandonaron estas categorías raciales a mediados del siglo XX? Finalmente, ¿por qué fue que esas mismas naciones volvieron a enumerar sus poblaciones con categorías etno-raciales a principios del siglo XXI? En corto, ¿qué explica los cambios en la clasificación de gente utilizada por los gobiernos latinoamericanos después de lograr su independencia? Estas cuestiones empíricas son de relevancia para investigadores interesados en estudios de la historia de raza, demografía, el nacionalismo, el conocimiento científico y los pueblos indígenas, al igual que su compleja interpelación.

\footnotetext{
* Center for Science, Technology, Medicine and Society (CSTMS) en la Universidad de California Berkeley, Berkeley CA, Estados Unidos da América (santiagojmolina@berkeley.edu).
} 
En el segundo capítulo Loveman se enfoca en la experiencias de la población Latinoamericana durante la época colonial, resumiendo las maneras en que las categorías etno-raciales fueron usadas para controlar y legalmente construir a la jerarquía social en la que vivían los habitantes de la colonia. Tratando casos y situaciones ya familiares a historiadores de la época colonial, Loveman ejemplifica la manera en que los gobernantes Españoles y Portugueses enumeraban a los coloniales como obreros, trabajadores o cuerpos militares, y de ésta manera mantenían el control doméstico mientras demostraban su poder ante el escenario internacional. A partir de este capítulo, el análisis rompe con la atención a las narrativas de los colonizados, el contenido cultural de cada país y el impacto de categorías específicas sobre la vida cotidiana de individuos y toma una posición macroanalítica. La metodología comparativa de Loveman, que cubre diecinueve países, la lleva a dar prioridad a hechos internacionales como la respuesta predominante a sus preguntas empíricas: la categorización de la población y la función de los censos sólo tienen sentido cuando se consideran las condiciones políticas y científicas internacionales de las épocas examinadas.

En el tercer capítulo, se explora el desarrollo del "racialismo" científico al nivel global y se describe la formación de un paradigma internacional de estadística que buscaba estandarizar la manera en que las naciones Latinoamericanas y sus gobiernos medían y reportaban el desarrollo y crecimiento de sus poblaciones. A principios del siglo XX, fue importante que las naciones de Latinoamérica se definieran y la estadística y demografía fueron mecanismos por los cuales los nuevos gobiernos independientes podían representar e indicar su "progreso" ante la comunidad internacional. De acuerdo al análisis del cuarto capítulo, el formato de los censos de Latinoamérica siguió las sugerencias del Congreso Internacional de Estadística pero con la importante atención hacia la medición del mestizaje en el país. Basando su análisis sobre el contenido de reportes oficiales de los diferentes órganos gubernamentales de estadística en diferentes países, Loveman describe la variación hacia el valor reconocido de los resultados de los censos y variación en cuanto a la definición e importancia del mestizaje. En diferentes países los cambios demográficos del país se interpretaban de modos idiosincráticos y señalaban particularidades del desarrollo social y económico de la nación.

La segunda mitad del libro describe los cambios en la categorías de los censos del siglo XX hasta el presente. El quinto capítulo detalla la manera en que los censos contribuyen a la naturalización de diferentes categorías etno-raciales y diferentes nociones de identidad nacional. Además, la publicación de los resultados del censo y las varias tabulaciones que proseguían en reportes oficiales afirmaban la existencia de un país entero, con fronteras claramente definidas. El sexto capítulo examina el impacto de los cambios a las preguntas de los censos sobre el reconocimiento de la diferencias entre grupos indígenas y el resto de la ciudadanía. Durante los mediados del siglo XX, la noción de "raza" comenzaba a perder su validez ante los ojos de la comunidad científica. Esto, en parte, segundo la autora fue la causa del reemplazo de preguntas con contenido racial con preguntas sobre diferentes 
características culturales y lingüísticas. Sin embargo, la autora afirma que estos cambios simultáneamente ocultaron la presencia de afrodescendientes en la imagen nacional en casi todos los países examinados. Con su enfoque cultural, éstos censos catalogaban la desaparición de hablantes de las lenguas indígenas y a la vez, describían el gradual reemplazo de sus formas de vida dentro del marco de la modernización de la nación.

Al finales del siglo XX, la autora muestra que los censos de países Latinoamericanos sufren otro cambio. Bajo presiones de movimientos sociales domésticos, en particular los movimientos indigenistas, y transnacionales, tanto organizaciones no-gubernamentales como organizaciones internacionales pidieron detener a los "proyectos de desarrollo" que buscaban llamar la asimilación de pueblos indígenas y grupos marginalizados. Varios movimientos sociales, particularmente en Brasil, Colombia y México, buscaban el reconocimiento y la re-valorización de la identidad afrodescendiente. A cambio de la posturas previas que pretendía ocultar estas diferencias intra-nacionales, como Loveman describe en el séptimo capítulo, los gobiernos de distintas naciones Latinoamericanas fueran presionadas a reconocer y apoyar la diversidad de sus poblaciones por medio de los conteos oficiales. Utilizando la documentación y enumeración de los diferentes pueblos y etnias del país, los gobiernos pudieron reconocer y comenzar a lidiar con desigualdades socioeconómicas que corresponden a diferencias etno-raciales.

En general, en los tres periodos que examina, Loveman encuentra que las comunidades científicas internacionales tuvieron un impacto sobre las decisiones de los órganos políticos responsables de la producción, distribución y análisis del censo poblacional. Éstas tres transiciones ilustran la naturaleza política de la producción del conocimiento. Conferencias y juntas internacionales de estadística, demografía, lingüística, antropología y biología surgen como mecanismos por los cuales diferentes ideologías sobre el valor científico de la clasificación etno-racial y del mestizaje son diseminadas a diferentes países. Loveman además incorpora una breve mención del rol de varios científicos que contribuyeron a las varias narrativas sobre la identidad nacional de sus países: por ejemplo de João Batista, Nina Rodriguez, y Gilberto Freyre en Brasil, René Morelos, Alcides Arguedas, Jorge Delance en Bolivia; Carlos Octavio Bunge en Argentina; y Manuel Gamio en México. Mientras estas breves discusiones indican algunas de la particularidades de las comunidades científicas en diferentes países, mucha de la variación identificada por Loveman en este ámbito requiere más detalle y elaboración. Además el vínculo entre estos campos científicos y la política local de sus países aún merita explicación ¿Qué conlleva el cambio del uso de categorías raciales dentro de la ciencia? ¿Cómo y por qué llegan diferentes individuos académicos y científicos a ocupar diferentes puestos dentro de la política? ¿Cuál es el impacto de las jerarquías sociales existentes dentro de los diferentes campos internacionales de investigación?

De manera eficaz, el libro deja abiertas muchas preguntas sobre las particularidades de casos específicos que piden la atención de investigadores en antropología, sociología, ciencias políticas, derecho e historia. Nacional Colors descifra la dimensión política de la clasificación etno-racial demostrando que la continuidad y los cambios en estos sistemas 
de clasificación en Latinoamérica, y probablemente en otras regiones, son el producto de la política internacional de desarrollo y modernización. En el actual momento histórico, varios órganos internacionales han institucionalizado la demanda de información sobre grupos etno-raciales, creando espacios de tensión y conflicto tanto internos como externos al país.

Loveman le da al lector mucho material empírico claramente articulado y organizado. Con éste material el lector puede reconocer una tensión central en la producción de la nación moderna: la necesidad de unificar la población bajo una narrativa de pertenencia y a la vez el reconocimiento de la diversidad etno-racial dentro de esa misma población. En el núcleo de la obra de Loveman, uno encuentra el reconocimiento que la definición de quién es o no es parte de la nación, es más una cuestión de poder simbólico que una cuestión sobre la objetividad de la estadística. La autora nota, “...las implicaciones de la clasificación etno-racial para la vida de los clasificados no depende de la formalidad o informalidad de la clasificación, si no en la naturaleza de la relación de poder entre los categorizadores y los categorizados." (p. 19, traducción propia).

\section{Sobre el autor}

Santiago José Molina es candidato doctoral en el Departamento de Sociología y miembro del Center for Science, Technology, Medicine and Society (CSTMS) en la Universidad de California Berkeley.

\section{Dirección}

Department of Sociology, University of California Berkeley

Barrows Hall 410,

94720 - Berkeley CA, Estados Unidos da América

Recibido para publicación en 12/04/2016

Aceptado para publicación en 19/07/2016 